IJIS | Indonesian Journal on Information System

\title{
SISTEM INFORMASI PROFIL BERBASIS WEB SEBAGAI MEDIA PROMOSI PADA WATERBOOM KOTA TERNATE
}

\section{INFORMATION SYSTEM BASED ON WEB PROMOTION PROFILE IN WATERBOOM TERNATE CITY}

\author{
Ilham Ishak ${ }^{1}$, Nuratni S Simin ${ }^{2}$ \\ Program Studi Manajemen Informatika, \\ Politeknik Sains dan Teknologi Wiratama Maluku Utara \\ ilham.ishak@gmail.com
}

\begin{abstract}
Abstrak
Waterboom Kota Ternate adalah salah satu wadah tempat bermain dan wisata yang bertempat dikota ternate provinsi Maluku utara, sistem promosi pada waterboom masih bersifat konvesional dimana sistem promosi pada waterboom masih menggunakan brosur dan media kertas lainnya, sehingga membutuhkan banyak biaya promosi dan operasional lainnya, banyak masyarakat sekitar yang ingin mengetahui informasi dan fasilitas yang disediakan pada tempat wisata waterboom tersebut dan bila ditinjau dari segi kelayakan dan kebutuhan maka waterboom telah memenuhi syarat menggunakan web sehingga akses informasi melalui internet dapat lebih efektif selain itu dapat mempermudah masyarakat luas untuk mengetahui informasi tentang profil dan fasilitas serta informasi pemesanan tiket masuk
\end{abstract}

Kata Kunci : Sistem Informasi, Promosi, Website

\section{Abstract}

Waterboom Ternate is one container playground and tours are held in the city of Ternate province of North Maluku, the promotion system in waterboom still conventional in which the promotion system in waterboom still use brochures and the media more paper, so it requires a lot of promotional costs and other operational, many communities around who want to know information and facilities provided at sites waterboom it and when viewed in terms of feasibility and needs then waterboom are qualified to use the web to access information via the internet can be more effective than that can facilitate the public to find out information about the profile and facilities as well as ordering information of admission

\section{Keyword: Information System, Promotion, Website}

\section{PENDAHULUAN}

Kemajuan teknologi informasi dan komunikasi saat ini banyak memberikan kemudahan bagi aktivitas manusia di segala bidang. Pengelolaan data-data untuk menjadi informasi yang sebelumnya rumit dan membutuhkan waktu yang lama dalam penyelesaiannya, menjadi cepat dan ringan bila dikerjakan menggunakan fasilitas teknologi. Akibatnya kebutuhan manusia akan teknologi semakin tinggi Karena dapat membantu efektifitas dan efisiensi suatu pekerjaan.

Waterboom Kota Ternate adalah salah satu wadah tempat bermain dan wisata yang bertempat dikota ternate provinsi Maluku utara, sistem promosi pada waterboom masih bersifat konvesional dimana sistem promosi pada waterboom masih menggunakan brosur dan media kertas lainnya, sehingga membutuhkan banyak biaya promosi dan operasional 
lainnya, banyak masyarakat sekitar yang ingin mengetahui informasi dan fasilitas yang disediakan pada tempat wisata waterboom tersebut dan bila ditinjau dari segi kelayakan dan kebutuhan maka waterboom telah memenuhi syarat menggunakan web sehingga akses informasi melalui internet dapat lebih efektif selain itu dapat mempermudah masyarakat luas untuk mengetahui informasi tentang profil dan fasilitas serta informasi tiket masuk

\section{Rumusan Masalah}

Berdasarkan uraian latar belakang di atas, maka rumusan masalah dalam penelitian ini yaitu: Bagaimana merancang sistem informasi berbasis web pada Waterboom Kota Ternate ? penelitian ini dibatasi pada perancangan sistem informasi tentang berita kegiatan waterboom, fasilitas yang tersedia bagi pengunjung, Informasi promosi dan pemesanan tiket masuk waterboom, sehingga dapat bermanfaat bagi masyarakat untuk mengetahui informasi fasilitas, berita kegiatan, dan informasi tiket masuk.

\section{LANDASAN TEORI}

\section{URL dan HTTP}

URL adalah kependekan dari Uniform Resource Locators adalah sebuah alamat di dalam internet yang terdiri dari dua bagian, Sistem informasi secara praktis membutuhkan pengambilan data yang lebih fungsional, meliputi fasilitas pencarian, front end update, dan catatan. HTTP memperbolehkan sekumpulan metode yang mengindikasikan permintaan tersebut. Pesan dipindahkan dalam format serupa dengan apa yang digunakan oleh Internet Mall yang didefinisikan oleh Multipurpose Internet Mall Extension.
HTTP juga digunakan sebagai protokol umum untuk kominikasi antar user agents dalam bentuk web browser. Pada dasarnya, HTTP merupakan protokol yang menerima semua permintaan dan memberikan respon terhadap permintaan tersebut. (Thoran, 2002).

\section{Klasifikasi Sistem}

Sistem merupakan suatu bentuk integrasi antara satu komponen dengan komponen yang lainnya. Karena sistem memiliki sasaran yang berbeda untuk setiap kasus yang terjadi yang ada didalam sistem tersebut. Menurut Al-barha bin ladjamudin (2005):

1. Sistem diklasifikasikan sebagai sistem abstrak (abstrak system) dan sistem fisik (phisical system). Sistem abstrak adalah sistem yang berupa pemikiran atau ide-ide yang tidak tampak secara fisik, misalnya : sistem teologia, yaitu sistem yang berupa pemikiranpemikiran hubungan antara manusia dan tuhan. Sedangkan sistem fisik merupakan sistem yang ada secara fisik, misalnya sistem komputer, sistem akuntansi dan sebagainya .

2. Sistem diklasifikasikan sebagai sistem alamiah (natural system) dan sistem buatan manusia (human made system). 10 Sistem alamiah adalah sistem yang terjadi melalui proses alam, tidak dibuat manusia, misalnya : perputaran bumi mengelilingi matahari. Sedangkan sistem buatan manusia adalah sistem yang dirancang oleh manusia. Sistem buatan manusia yang melibatkan interaksi antara manusia dengan mesin disebut human machine system, misalnya : sistem informasi.

3. Sistem diklasifikasikan sebagai sistem tertentu (deterministik system) dan sistem tak tertentu (probabilistik 
system). Sistem tertentu adalah sistem yang beroperasi dengan tingkah laku yang sudah dapat diprediksi, misalnya : sistem komputer. Sedangkan sistem tak tentu adalah sistem yang kondisi masa depannya tidak dapat di prediksi karena mengandung unsur probabilitas.

4. Sistem diklasifikasikan sebagai sistem tertutup (closed system) dan sistem terbuka (open system). Sistem tertutup merupakan sistem yang tidak berhubungan dan tidak terpengaruh dengan lingkungan luarnya. Sedangkan sistem terbuka adalah sistem yang berhubungan dan terpengaruh dengan lingkungan luarnya.

\section{Pengertian Web}

Nuruddin (2013) WWW (World Wide Web) atau juga dikenal dengan WEB adalah salah satu layanan yang didapat oleh pemakai komputer yang terhubung ke internet. Website atau situs dapat diartikan sebagai kumpulan halaman-halaman yang digunakan untuk menampilkan informasi teks, gambar diam atau gerak, animasi, suara, dan atau gabungan dari semuanya itu baik yang bersifat statis maupun dinamis yang membentuk satu rangkaian bangunan yang saling terkait dimana masing-masing dihubungkan satu sama lain. Sedangkan menurut A.Taufiq Hidayatullah, web adalah bagian paling terlihat sebagai jaringan terbesar dunia, yakni internet

\section{Pengertian HTML}

Sunarfrihantono (2002:1) HTML (Hypertext Markup Language) merupakan salah satu format yang digunakan dalam pembuatan dokumen dan aplikasi yang berjalan di halaman web. Oleh karena itu agar dapat membuat program aplikasi diatas halamn web, terlebih dahulu harus mengenal dan menguasai HTML. Protokol yang digunakan untuk mentransfer data antara web server ke web browser ialah HTTP (Hypertext Transfer Protocol). Protokol ini mentransfer dokumendokumen web yang ditulis atau berformat HTML (Hypertext Markup Language).

\section{Pengertian PHP}

Saputra (2011:1) PHP atau yang memiliki kepanjangan PHP Hypertext Preprocessor merupakan suatu bahasa pemograman yang difungsikan untuk membangun suatu website dinamis. PHP menyatu dengan kode HTML, makasudnya adalah beda kondisi. HTML di gunakan sebagai pembangun atau pondasi dari kerangka layout web, sedangkan PHP difungsikan sebagai prosesnya sehingga dengan adanya PHP tersebut, sebuah web akan sangat mudah dimaintenance. PHP berjalan pada sisi server sehingga PHP disebut juga sebagai bahasa Server Side Scripting. Artinya bahwa dalam setiap/untuk menjalankan PHP wajib adanya sebuah server

\section{Pengertian MySQL}

Saputra (2011:69) secara umum, database berfungsi sebagai tempat atau wadah untuk menyimpan, mengklasifikasikan data secara professional. MySQL bekerja menggunakan SQL Language (Structure Query Language) itu dapat diartikan bahwa MySQL merupakan standar penggunaan database didunia untuk pengolahan data. Sedangkan Raharjo (2011:21) MySQL merupakan RDBMS atau (server database) yang mengelolah database dengan cepat menampung dalam jumlah sangat besar dan dapat diakses oleh banyak user. Begitu juga menurut 
Wahana Komputer (2010:5) MySQL adalah sebuah manajemen system database server yang mampu menangani beberapa user, yaitu mampu menangani beberapa instruksi sekaligus dari beberapa user dalam satu waktu.

\section{Pengertian CSS}

Kurniawan (2008:1) dalam buku yang berjudul desain web praktis dengan CSS menjelaskan bahwa CSS atau Cascading Style Sheets adalah sebuah dokumen yang berisi aturan yang digunakan untuk memisahkan isi dengan layout dalam halaman-halaman web yang dibuat. CSS memperkenalkan "template" yang berupa style untuk dibuat dalam mengizinkan penulisan kode yang lebih mudah dari halaman-halaman web yang dirancang. Sedangkan Jayan (2010:2) dalam buku CSS untuk orang awam yang menjelaskan tentang kegunaan CSS adalah untuk mengatur tampilan dokumen HTML, contohnya seperti pengaturan jarak antar baris, teks, warna, dan format border bahkan penampilan file gambar

\section{Pengertian DFD}

Data flow diagram atau disingkat DFD merupakan suatu diagram yang menggambarkan alur data dalam suatu entitas ke sistem atau sistem ke entitas (Saputra, 46:2013). DFD juga dapat diartikan sebagai teknis grafis yang menggambarkan alir data transformasi yang digunakan sebagai perjalanan data dari input atau masukkan menujukeluaran atau output.

\section{METODE PENELITIAN}

Dalam merancang sistem dibutuhkan data dan informasi untuk menganalisa terhadap perancangan sistem. Metode yang dilakukan adalah metode pengumpulan data yang ada dilapangan. Metode tersebut antara lain :

a. Wawancara (interview)

Peneliti akan mewawancarai secara langsung kepada manager operasional Waterboom Kota Ternate untuk mendapatkan informasi terkait dengan kebutuhan penelitian.

b. Pengamatan (observasi)

Untuk mendapatkan data penelitian, peneliti melakukan Observasi, di Waterboom Kota Ternate.

c. Metode dokumentasi dalam penelitian ini dimaksudkan untuk memperoleh data berbentuk dokumentasi, berupa gambar-gambar yang ada di Waterboom Kota Ternate

\section{Analisis Sistem}

Analisis sistem merupakan tahapan paling awal dari pengembangan sistem yang menjadi fondasi menentukan keberhasilan sistem informasi yang dihasilkan nantinya. Analisis sistem adalah sebuah istilah yang secara kolektif mendeskripsikan fase-fase awal pengembangan awal. Rosa A. S \& $\mathrm{M}$. Shalahuddin (2013:18) Kegiatan analisis sistem kegiatan untuk melihat sistem yang sudah berjalan, melihat bagian mana yang bagus dan tidak bagus, dan kemudian mendokumentasikan kebutuhan yang akan dipenuhi dalam sistem yang baru. Analisis sistem adalah pemecahan masalah yang menguraikan bagian-bagian komponen tersebut bekerja dan berinteraksi untuk mencapai tujuan mereka (Al Fatta, 2007:44).

\section{Analisa sistem yang berjalan}

Sistem yang berjalan pada Waterboom Kota Ternate masih sangat manual yaitu informasi bermula pada manager 
operasional Waterboom Kota Ternate kemudian di sampaikan kepada marketing, selanjutnya marketing melakukan promosi mengenai Waterboom Kota Ternate melalui media cetak (baliho, brosur, Koran) dan media elektronik (televisi dan radio), kemudian pengunjung harus datang ke waterboom kota ternate untuk membeli tiket di loket dan petugas loket (kasir) menginput data pengunjung kemudian data tersebut tersimpan kedalam database dan tiket tersebut di cetak oleh kasir dan diberikan kepada pengunjung, Kemudian admin dapat melihat laporan per hari. Adapun sistem yang sedang berjalan pada Waterboom Kota Ternate dapat dilihat pada gambar dibawah ini

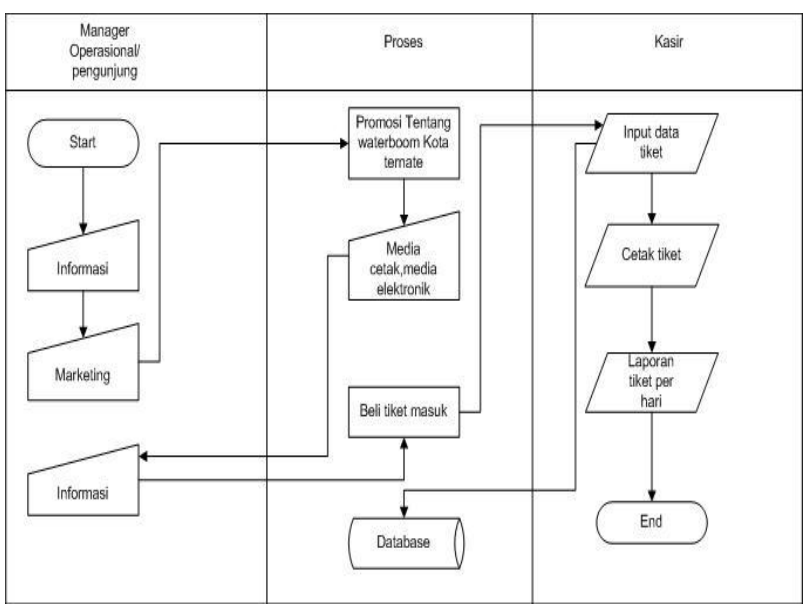

Gambar 1 : Sistem yang berjalan

Kelemahan-kelemahan yang terdapat pada sistem yang sedang berjalan di antaranya :

1. Informasi yang diberikan kepada masyarakat masih sangat manual masyarakat yang ingin mengetahui tentang fasilitas dan informasi tiket harus melihat pada brosur tersebut sehingga penigkatan pengunjung pun masih minim.

2. Membutuhkan waktu yang cukup lama jika pembelian tiket pada harihari libur karena menunggu dalam antrian.

\section{Analisys system yang di usulkan}

Dari kelemahan-kelemahan sistem yang berjalan pada Waterboom Kota Ternate maka diusulkan sistem yang baru untuk mengatasi kelemahan-kelemahan pada sistem yang lama seperti pada gambar di bawah ini :

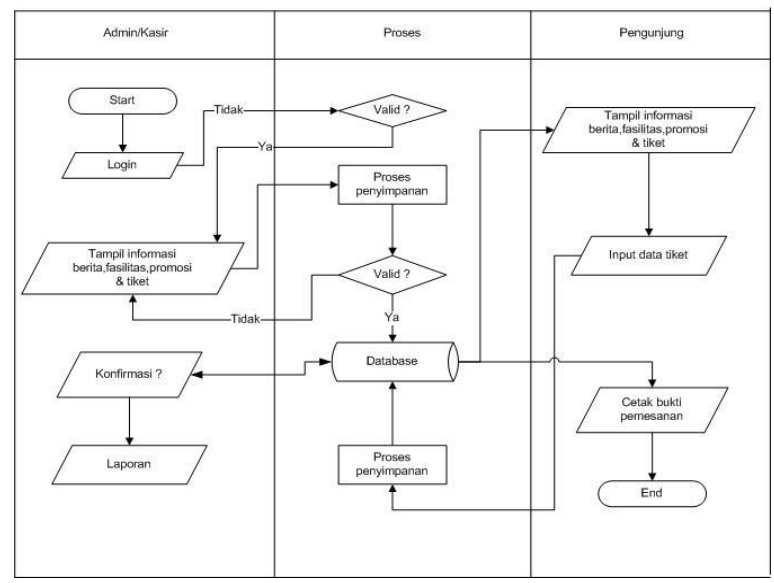

Gambar 2 : Sistem yang diusulkan

Alat dan Bahan

Aplikasi yang digunakan dalam penelitian ini berupa perangkat lunak (software) seperti:

1. Sistem Operasi Windows 7 Ultimate.

2. Notepad ++ 6.5.4 untuk desain HTML dan PHP

3. Microsoft Visio 2007 untuk membuat flowchart.

4. Web server XAMPP 1.8.3 (Apache, MySQL)

5. Bahasa pemograman HTML, PHP, SQL dan CSS.

Bahan yang digunakan dalam penelitian ini berupa perangkat keras (hardware) PC Laptop dengan spesifikasi, sebagai berikut:

1. Processor intel 1005M (1.9 GHz,2MG L3 cache)

2. Mainboard Intel.

3. LCD LED HD 14.0"

4. am 2 GB DDR3.

4. Hardisk 320 GB. 
5. Keyboard.

6. Mouse Optic.

\section{PERANCANGAN SISTEM}

Tahap perancangan sistem mempunyai dua tujuan utama yaitu memenuhi kebutuhan kepada pengguna dan untuk memberikan gambaran yang jelas dan rancangan yang lengkap. Halhal yang perlu didalam perancangan sistem meliputi Diagram Konteks, Data Flow Diagram (DFD), Entity Relationship Diagram (ERD), Referential Integrity, dan Rancang tampilan program

\section{Diagram Konteks}

Diagram konteks merupakan gambaran umum sistem yang nantinya akan di buat. Secara uraian dapat dikatakan bahwa diagram konteks itu berisi siapa saja yang memberikan data (inputan) ke sistem, serta kepada siapa data informasi itu diberikan (melalui sistem). Diagram konteks dari Sistem Informasi Berbasis Web pada Waterboom Kota Ternate sebagai berikut

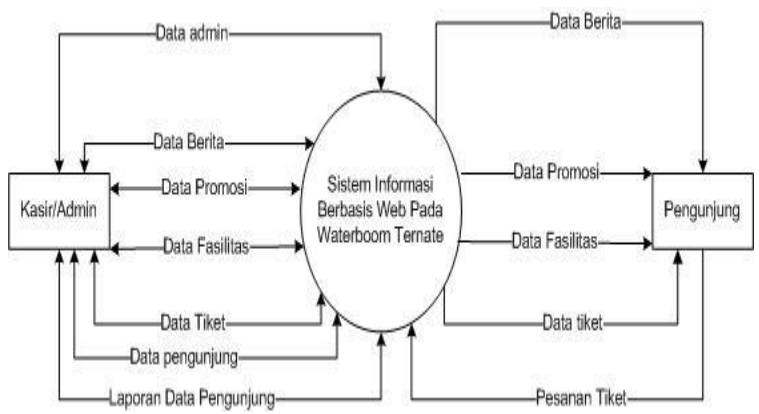

Gambar 3 : Diagram Konteks

\section{Diagram Flow Data (DFD) DFD Level 1}

DFD level 1 merupakan penjelasan lebih rinci terhadap proses-proses yang terjadi pada aplikasi. DFD level 1 memberikan gambaran yang lebih dan digambarkan pula penyimpan data dan proses yang terjadi di dalam aplikasi., berikut merupakan diagram flow data level 1 adalah sebagai berikut:

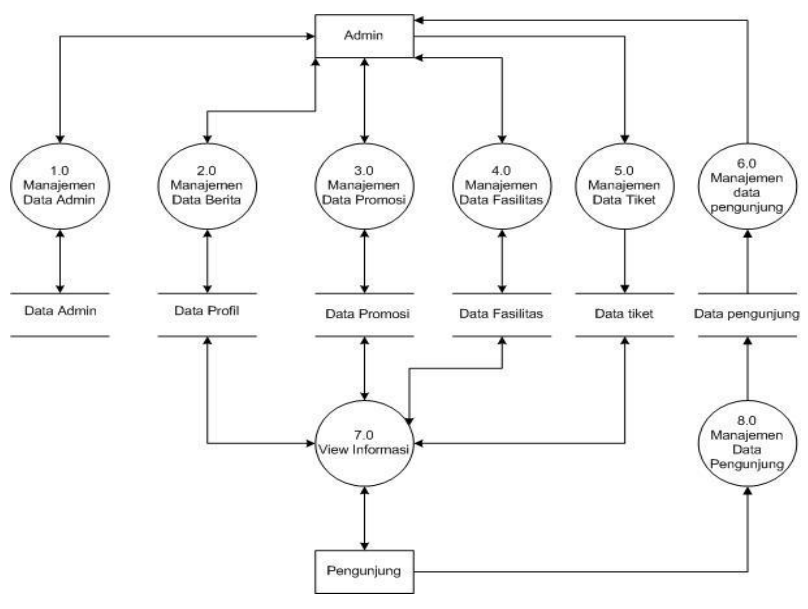

Gambar 4 : Diagram Level 1

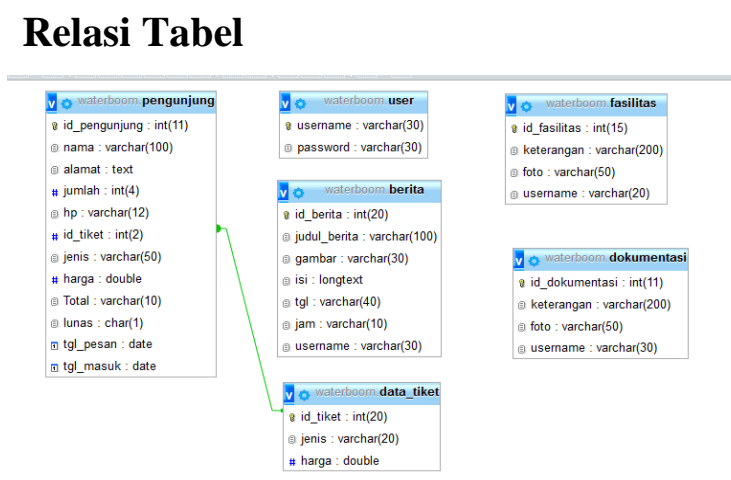

Gambar 5 : Relasi Tabel

\section{Perancangan Tabel databse}

Perancangan basis data merupakan langkah untuk menentukan basis data yang diharapkan dapat mewakili seluruh kebutuhan pengguna. Komponen komponen penting yang terdapat dalam perancangan database adalah :

a. Entitas, merupakan objek atau kejadian yang mewakili sesuatu yang nyata. Pada model relational, entitas akan menjadi tabel.

b. Atribut, adalah item data yang menjadi bagian dari suatu entitas atau yang mendeskripsikan karakteristik dari entitas.

c. Record, adalah kompulan elemen elemen yang saling berkaitan 
menginformasikan suatu entitas secara lengkap. Misalnya informasi nama, alamat dll.

d. Data value (nilai atau isi data), adalah data aktual atau informasi yang disimpan pada tiap data elemen atau atribut.

e. File, adalah kumpulan record record sejenis yang mempunyai panjang elemen yang sama.

f. Hubungan, adalah kaitan dengan dua entitas.

g. Kunci Primer (primary key), adalah kunci yang dipilih sebagai kunci utama untuk mengidentifikasikan barisan dalam tabel.

h. Kunci Tamu ( Foreign Key), adalah atribut yang menunjuk ke kunci primer pada tabel lain.

\section{Tabel Admin}

Tabel admin digunakan untuk menyimpan data admin. Spesifikasi dari tabel admin adalah sebagai berikut

Tabel 1. Tabel Admin

\begin{tabular}{|l|l|l|l|}
\hline \multicolumn{1}{|c|}{ Field } & \multicolumn{1}{|c|}{ Type } & Length & $\begin{array}{l}\text { Primary } \\
\text { Key }\end{array}$ \\
\hline $\begin{array}{l}\text { usernam } \\
\text { e }\end{array}$ & varchar & 30 & $*$ \\
\hline $\begin{array}{l}\text { passwor } \\
\text { d }\end{array}$ & Varchar & 30 & \\
\hline
\end{tabular}

\section{Tabel Berita}

Tabel berita digunakan untuk menyimpan data berita kegiatan yang di laksanakan di Waterboom Ternate. Spesifikasi dari tabel berita adalah sebagai berikut

Tabel 2. Tabel Berita

\begin{tabular}{|l|l|l|l|}
\hline Field & Type & $\begin{array}{l}\text { Lengt } \\
\text { h }\end{array}$ & $\begin{array}{l}\text { PrimaryK } \\
\text { ey }\end{array}$ \\
\hline id_berita & Int & 20 & $*$ \\
\hline $\begin{array}{l}\text { judul_beri } \\
\text { ta }\end{array}$ & $\begin{array}{l}\text { Varcha } \\
\text { r }\end{array}$ & 100 & \\
\hline
\end{tabular}

\begin{tabular}{|l|l|l|l|}
\hline gambar & $\begin{array}{l}\text { Varcha } \\
\mathrm{r}\end{array}$ & 30 & \\
\hline isi & $\begin{array}{l}\text { longte } \\
\mathrm{xt}\end{array}$ & & \\
\hline tgl & $\begin{array}{l}\text { Varcha } \\
\mathrm{r}\end{array}$ & 40 & \\
\hline jam & $\begin{array}{l}\text { Varcha } \\
\mathrm{r}\end{array}$ & 10 & \\
\hline username & $\begin{array}{l}\text { Varcha } \\
\mathrm{r}\end{array}$ & 30 & \\
\hline
\end{tabular}

\section{Tabel Promosi}

Tabel promosi digunakan untuk menyimpan data yang berhubungan dengan promosi tentang Waterboom Ternate. Spesifikasi dari tabel promosi adalah sebagai berikut

Tabel 3. Tabel Promosi

\begin{tabular}{|l|l|l|l|}
\hline Field & Type & Length & $\begin{array}{l}\text { Primary } \\
\text { Key }\end{array}$ \\
\hline $\begin{array}{l}\text { id_prom } \\
\text { osi }\end{array}$ & Int & 11 & $*$ \\
\hline $\begin{array}{l}\text { keterang } \\
\text { an }\end{array}$ & Varchar & 200 & \\
\hline foto & Varchar & 50 & \\
\hline $\begin{array}{l}\text { usernam } \\
\text { e }\end{array}$ & Varchar & 30 & \\
\hline
\end{tabular}

\section{Tabel Fasilitas}

Tabel fasilitas digunakan untuk menyimpan informasi tentang fasilitas yang ada pada Waterboom Ternate. Spesifikasi tabelnya sebagai berikut

Tabel 4. Tabel Fasilitas

\begin{tabular}{|l|l|l|l|}
\hline Field & Type & Length & $\begin{array}{l}\text { Primary } \\
\text { Key }\end{array}$ \\
\hline $\begin{array}{l}\text { id_fasilit } \\
\text { as }\end{array}$ & Int & 15 & $*$ \\
\hline $\begin{array}{l}\text { keterang } \\
\text { an }\end{array}$ & Varchar & 200 & \\
\hline foto & Varchar & 50 & \\
\hline
\end{tabular}




\begin{tabular}{|l|l|l|l|}
\hline $\begin{array}{l}\text { usernam } \\
\mathrm{e}\end{array}$ & Varchar & 20 & \\
\hline
\end{tabular}

\section{IMPLEMENTASI SISTEM}

Tempilan Halam Utama Profil
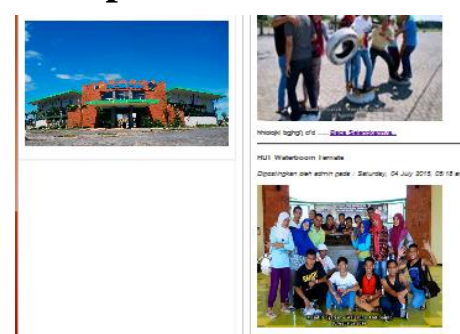

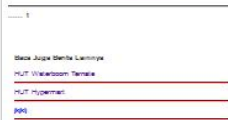

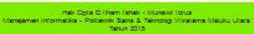

Gambar 6 : Halaman Utama Profil

\section{Halaman Utama Profil dan Fasilitas}

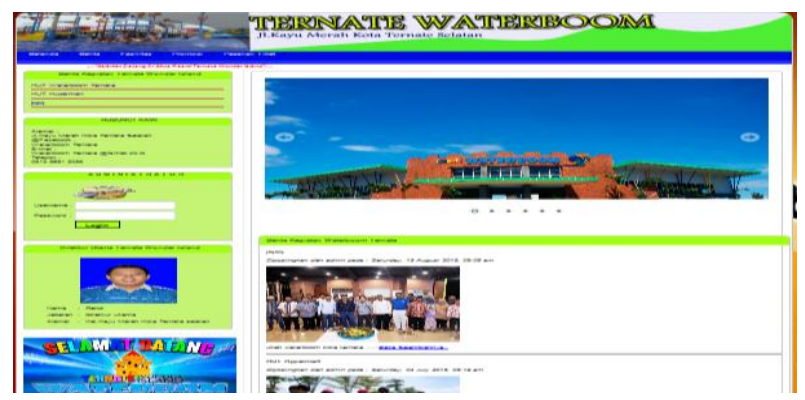

Gambar 7 : Halaman Utama Profil

\section{Form Login Admin}

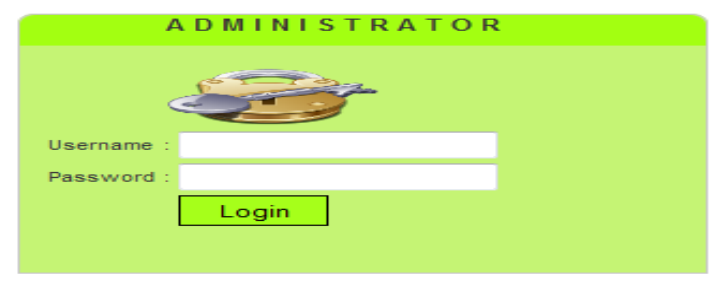

Gambar 8 : Form Login Admin

\section{Form Halaman Utama Administrator}

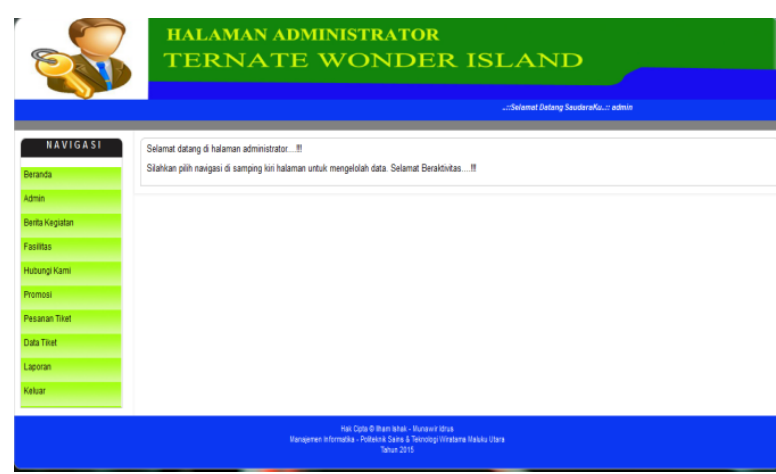

Gambar 9 : Form Halaman Utama Admin

Halaman Form Berita Kegiatan Untuk Admin

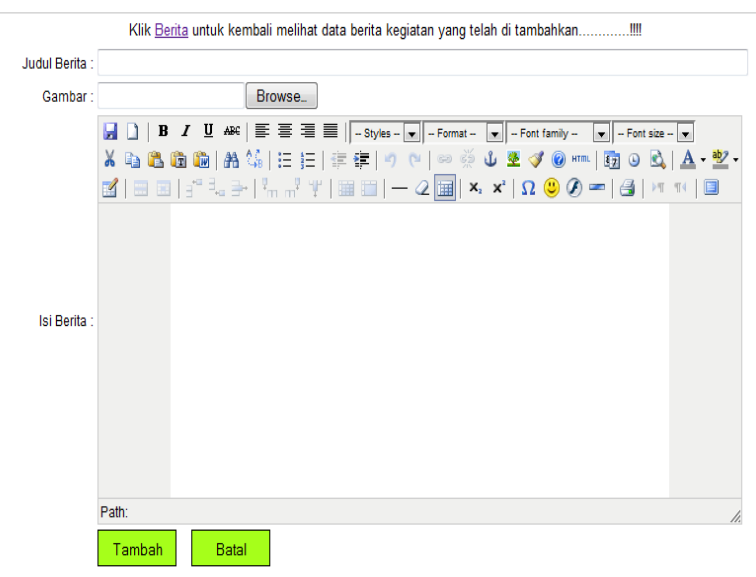

Gambar 10 : Halaman Form Berita Kegiatan Untuk Admin

\section{Tampilan form Berita dan Kegiatan}

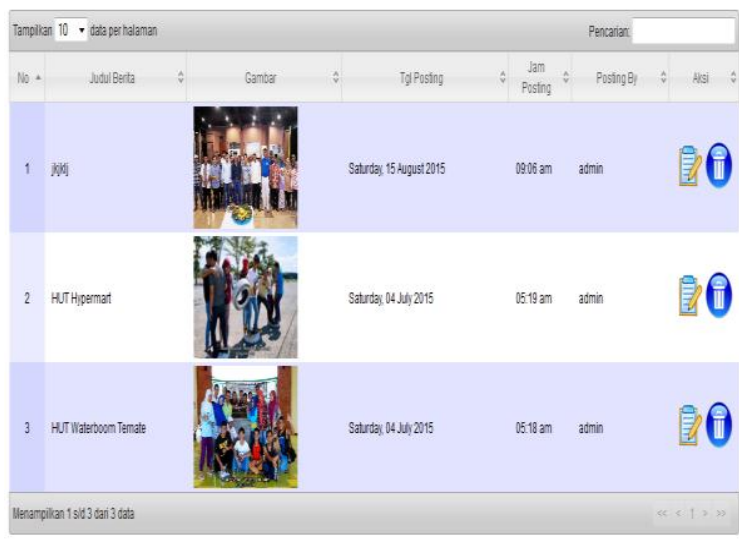

Gambar 11 : Form Pendaftaran

\section{Form Fasilitas Untuk Admin}

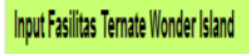

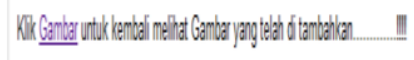

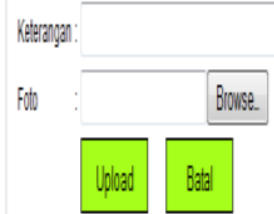


Gambar 12 : Form Fasilitas Untuk Admin

\section{KESIMPULAN}

Sistem informasi profil berbasis web sebagai media promosi pada waterboom kota ternate ini dirancang menggunakan elemen-elemen sistem seperti notepad ++, Xampp, Sistem operasi Windows 7 sehingga hasil Dari Perancangan sistem tersebut dapat disimpulkan bahwa sistem yang baru dapat mempermudah bagi masyarakat untuk mengetahui informasi tentang Waterboom Kota Ternate di manapun dan kapanpun. Perancangan system informasi ini juga dapat membantu perusahan untuk meningkatkan pengunjung yang masuk ke Waterboom Kota Ternate.

Berdasarkan kesimpulan di atas, maka diajukan saran sebagai berikut.: 1. dapat menerapkan Sistem ini untuk mempermudah mempromosikan tempat wisata waterboom pada masyarakat sekitar tanpa menggunakan media kertas dan brosur: 2. Peneliti menyadari hasil dari perancangan sistem ini masih jauh dari kesempurnaan, untuk itu disarankan agar dapat dikembangkan oleh peniliti selanjutnya

\section{DAFTAR PUSTAKA}

Sanyoto Gondodiyoto. 1988. Pengantar Komputer Dan Komputerisasi, Mandar Maju, Bandung

Sunarfrihantono Bimo. 2002. PHP dan $M y S Q L$ untuk web.ANDI, Yogyakarta

Moekijat. 2005. Pengantar Sistem Informasi Manajemen. Mandar Maju, Bandung

Al Fatta Hanif. 2007. Analisis dan Perancangan Sistem Informasi. Penerbit Andi. Yogyakarta
Kurniyawan Budi. 2008. Desain web praktis dengan CSS. PT. Elex Media Komputindo,Jakarta.

Jayan. 2010. CSS Untuk Orang Awam (membangun website tanpa table,fleksibel dan efektif). Maxikom, Palembang.

Wahana Komputer. 2010. Panduan Belajar MySQL Database Server. Mediakita, Jakarta

Saputra Agus. 2011. Trik dan Solusi Jitu Pemrograman PHP. PT. Elex Media Komputindo, Jakarta. --.2013.menyelesaikan website 12 juta secara professional. PT. Elex Media Komputindo, Jakarta

Raharjo Budi dkk. 2012. Modul Pemrograman WEB (HTML, $P H P \& M y S Q L)$.

Raghib Nuruddin. 2013. Pengertian \& Definisi Web. Tersedia: http://raghibnuruddin217.blogspot .com/. (Diakses pada tanggal 5 Maret 2015,20.38 WIT)

M. Shalahuddin \& Rosa A. S. 2013. Rekayasa Perangkat Lunak terstruktur dan berorientasi objek, informatika, Bandung.

Taufik Rohmat. 2013. Sistem Informasi Manajemen. Graha Ilmu, Yogyakarta.

Rudi Banu Kuncoro, Pembuatan Website Tempat Pariwisata Rumah Dome New Nglepen, Speed Journal Indonesian Jurnal on Computer Science - Vol 10 No 2 - Agustus 2012, ISSN 1979 - 9330, speed.unsa.ac.id

Suyatno, Tri Irianto $\mathrm{Tj}$, Pembuatan Website Profil Sekolah Dasar Negeri 03 Karangsari, Indonesian Jurnal on Networking and Security (IJNS) - ijns.org, IJNS Volume 2 
No 1 - Januari 2013 - ISSN: 23025700

Ika Nur Indah, Lies Yulianto, Pembuatan

Website Sebagai Sarana Promosi

Produk Kelompok Pidra Desa

Gawang Kecamatan Kebonagung

Kabupaten Pacitan, IJCSS) 15 -

Indonesian Jurnal on Computer

Science Speed - FTI UNSA Vol 10

No 1 - Februari 2013 -

ijcss.unsa.ac.id, ISSN 1979 - 9330

Robby Rachmatullah, Perancangan Sistem

Pemesanan Tiket Bus Online

Berbasis Web, IJNS - Indonesian

Journal on Networking and

Security - Volume 4 No 1 - Januari

2015, ISSN: 2302-5700 (Print)

2354-6654 (Online)

Ginanjar Akbar, Tri irianto Tjendrowaseno, Website Profil Sekolah Sebagai Media Informasi Dan Promosi, IJNS - Indonesian Journal on Networking and Security - Volume 4 No 1 - Januari 2015 - ijns.apmmi.org, ISSN:

2302-5700 (Print) 2354-6654

(Online) 